\title{
РОССИЙСКИЙ РЫНОК ФИНАНСОВ В УСЛОВИЯХ ЦИФРОВИЗАЦИИ
}

\author{
Исраилова 3.P., \\ Арсанукаева Б.У. \\ ФГБОУ ВО «Чеченский государственный университет», \\ г. Грозный, Россия
}

В статье рассмотрено влияние внедрения новых ичифровых технологий и их совершенствования на развитие финансового рынка. Автором выявлены основные факторы, способствуюшие развитии циирровой экономики. Разработань рекомендации по устранению рисков циифровизации и совершенствованию управления.

Ключевые слова: финансовые технологии, финансовый рынок, субъекты финансового рынка, финансовые инструменты, банки, стартапы, инвестиции

В современное время - в век информационных технологий и компьютеризации - цифровая экономика затрагивает практически каждый аспект нашей жизни. Цифровая экономика в последние несколько лет стала популярна во всех высокоразвитых странах, в том числе и в России. Особенно с момента утверждения такой государственной программы как «Цифровая экономика Российской Федерации».

Исходя из мировых тенденций и последних веяний внешней политики перед Россией стоит задача повышения конкурентоспособности в глобальном смысле, а также укрепления национальной безопасности. Не маловажную роль в разрешении данной задачи играет развитие цифровой экономики в стране. На сегодняшний день некоторые элементы цифровой экономики уже довольно неплохо функционируют, например, электронное правительство. Общение с государством постепенно переходит на электронную платформу, производится массовый перенос документов и коммуникаций на цифровые носители, разрешается использование электронной подписи.

Однако не все элементы уже так успешно движутся по направлению к цифровизации. Чтобы понять, какие элементы являются отстающими, а какие передовыми, необходимо иметь понятие о том, как же измерить уровень развития цифровой экосистемы в конкретных составляющих и в стране в целом.

Теоретическую базу исследования составили комментарии к действующему законодательству, монографии отечественных авторов: В.А. Белов. С.М. Бойцов, Е.В. Алексеева, А.В. Габов, К.С. Зиновьев, Г.Н. Шевченко, Е.В. Терехова, С.П. Гришаев, В.М. Гордон, С.М. Барац, Н.О Нерсесов, М.М. Агарков.

Нормативную основу исследования составляют нормы Гражданского кодекса Российской Федерации, Федерального закона «Об акционерных 
обществах», Федерального закона «О рынке ценных бумаг» иные нормативноправовые акты.

В работе были использованы следующие методы научного исследования: анализ нормативно-правовой документации, классификация, обобщение. Общетеоретическую и методологическую основу работы составляют федеральные законы, государственная программа, закономерности экономической науки, а также методологии [1].

Добиться устойчивости в современном бизнесе в настоящее время труднее, чем когда-либо в прошлом. Сложно завоевать основательное конкурентное преимущество, которое позволит оказаться на вершине, а будучи на ней, трудно не упасть. К примеру, согласно американской статистике, около $52 \%$ компаний, числившихся в рейтинге 500 крупнейших мировых компаний (Fortune 500) в 2000-м году, уже не существуют. Другой характерный показатель: средняя продолжительность жизненного цикла компаний, входящих в рейтинг Standard \& Poor's 500, который в 1960 году составлял 60 лет, по некоторым прогнозам, снизится до 12 лет к 2020 году [2].

Вероятнее всего, причиной такого существенного сокращения срока пребывания на вершине является переход всех сфер бизнеса на цифровую платформу. Причем свидетелями и участниками так называемого «Цифрового переворота» являемся мы.

Цифровая трансформация-это интеграция цифровых технологий во все сферы бизнеса, коренным образом меняющая то, как протекает деятельность и предоставляется ценность для клиентов. Это также культурное изменение, которое требует от организаций постоянно оспаривать статус-кво, экспериментировать и чувствовать себя комфортно при возникновении сложностей. Цифровая трансформация является императивом для всех предприятий, от малого до крупного предприятия. Это сообщение приходит через громкий и ясный, казалось бы, каждый лейтмотив, панельная дискуссия, статья или исследование, связанные с тем, как бизнес может оставаться конкурентоспособным и актуальным, поскольку мир становится более цифровым. То, что не ясно для многих бизнес-лидеров, - это то, что означает цифровая трансформация.

Поскольку цифровая трансформация будет выглядеть по-разному для каждой компании, может быть трудно определить определение, которое применяется ко всем. Однако в общих чертах определяем цифровую трансформацию как интеграцию цифровых технологий во все сферы бизнеса, приводящую к фундаментальным изменениям в том, как работают предприятия и как они обеспечивают ценность для клиентов. Кроме того, это культурное изменение, которое требует от организаций постоянно оспаривать статус-кво, часто экспериментировать и чувствовать себя комфортно с неудачей. Иногда это означает отказ от давних бизнес-процессов, на которых строились компании, в пользу относительно новых практик, которые все еще определяются. 
Хотя цифровая трансформация будет широко варьироваться в зависимости от конкретных задач и потребностей организации, существует несколько констант и общих тем среди существующих тематических исследований и опубликованных рамок, которые все деловые и технологические лидеры должны учитывать, когда они приступают к цифровой трансформации.

Например, эти элементы цифрового преобразования часто цитируются:

- потребительский опыт;

- оперативная гибкость;

- культура и лидерство;

- обеспечение рабочей силой;

- интеграция цифровых технологий.

Несмотря на растущее значение цифровых инноваций, концептуализируемых как инновационные цифровые решения, которые позволяют осуществлять цифровую трансформацию бизнеса в различных отраслях промышленности, эмпирические исследования факторов, связанных с цифровыми инновациями, все еще являются скудными, создавая разрыв в знаниях. Чтобы заполнить этот пробел, в настоящем документе ставится цель изучить влияние цифровой ориентации и цифровых возможностей на цифровые инновации, а также опосредующее влияние цифровых инноваций на связь между эффективностью организации и цифровой ориентацией, а также цифровыми возможностями.

Цифровые технологии - это электронные инструменты, системы, устройства и ресурсы, которые генерируют, хранят или обрабатывают данные. Хорошо известные примеры включают социальные медиа, онлайн-магазины, мультимедиа и мобильные телефоны [1].

Цифровые технологии оказывают влияние на инновации во всех отраслях экономики, в том числе в таких традиционных отраслях, как сельское хозяйство, автомобильная промышленность и розничная торговля. Аналогичные тенденции в различных секторах включают в себя то, что Интернет вещей и данных становятся ключевыми факторами для инноваций, инновационные циклы ускоряются, инновации в сфере услуг приобретают все большее значение, а совместные инновации имеют все большее значение. Отраслевая динамика обусловлена различиями в возможностях, которые такие технологии предлагают для инноваций в продуктах, процессах и бизнесмоделях, а также различиями в типах данных, необходимых для инноваций, и условиях внедрения цифровых технологий. Проведенный анализ требует пересмотра комплекса мер инновационной политики для обеспечения их дальнейшей эффективности и решения возникающих проблем. Секторальный подход необходим при разработке инновационной политики в некоторых областях, особенно в отношении доступа к данным и политики внедрения цифровых технологий. Нынешняя направленность инновационной политики на стимулирование НИОКР для достижения целевых показателей интенсивности НИОКР также требует тщательного изучения. 
Экономическое воздействие цифровых технологий дает возможность глубоко изучить трансформацию ИКТ и ее важнейшую роль в усилении методов и методик, включающих финансовые инструменты. Он предоставляет ученым и директивным органам оригинальные и практические инструменты для оценки и оценки процесса распространения и включения ИКТ. Основная идея книги заключается в том, что давно назрела необходимость в согласованной стратегии внедрения ИКТ-технологий в общество.

Социальные различия в использовании ИКТ сохраняются и в некоторых случаях расширяются, однако, несмотря на это, существует нехватка исследований по устранению цифрового неравенства. Это имеет особое значение с учетом того, что относительные уровни использования ИКТ, инвестиций и исследований часто могут служить объяснением различий в экономических показателях между промышленно развитыми странами. Авторы предлагают индикаторы и индексы цифрового развития и электронной инклюзии (и ее обратной стороны-электронной эксклюзии) для оценки взаимосвязи между инклюзивными ИКТ и более широкой экономической и социальной деятельностью в России [3].

Финансовый рынок России включает в себя множество направлений трендов, описанных в рисунке 1 ниже.

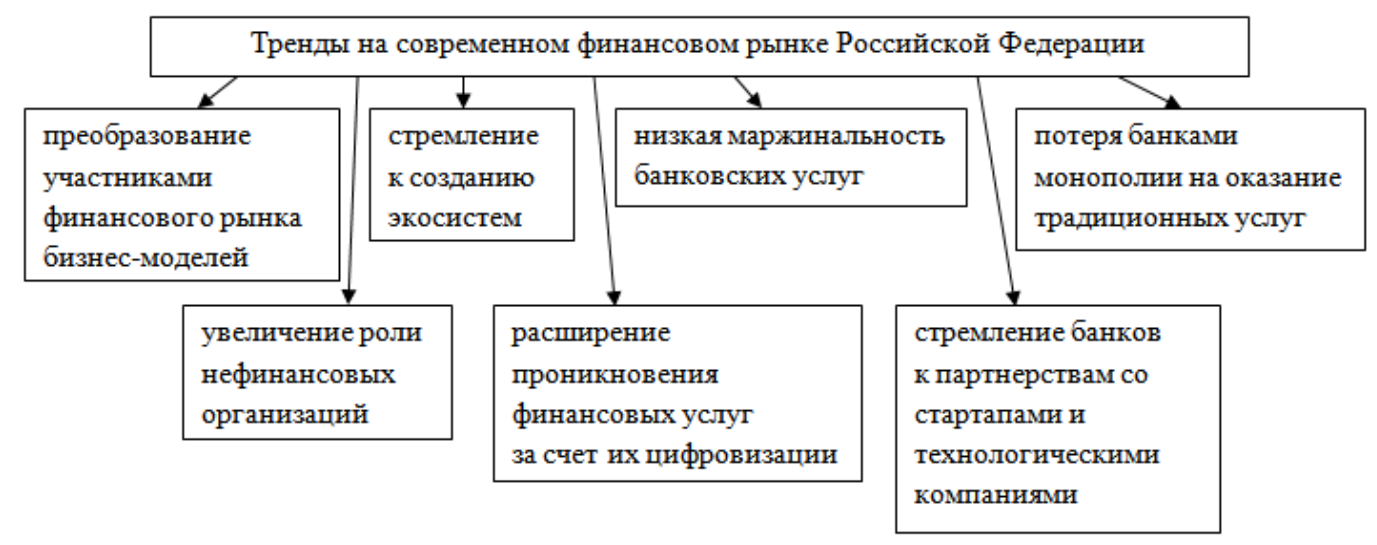

Рис. 1 - Тренды на современном финансовом рынке РФ [3]

Развитие финансовых технологий в виде внедрения инновационных продуктов и сервисов модернизирует традиционные направления оказания финансовых услуг.

Примеры внедрения инновационных продуктов в области оказания финансовых услуг:

- платежи и перевод, а именно онлайн-платежи, онлайн-переводы, обмен валюты p2p, терминалы-смарт, облачные кассы и т.д;

- финансирование, а именно краудфандинг, p2p потребительское и бизнес кредитование;

- управление капиталом, a именно социальный трейдинг, робоэдвайзинг, сервис целевых накоплений, алгоритмическая биржевая торговля. 
Глобальной тенденцией является повышение эффективности деятельности регуляторов путем применения новых технологий.

Совершенствование существующих методов надзора и регулирования с помощью новых технологий для обеспечения эффективных способов выявления и оценки рисков, сбора и анализа данных - всё это про широко использующийся в современных условиях термин «SupTech». На российском финансовом рынке данная тенденция выражается в совершенствовании механизмов взаимодействия Центрального Банка РФ и поднадзорных организаций путем развития личного кабинета участников информационного обмена, использования новых форматов предоставления надзорной информации.

Термин «RegTech» является противоположным вышерассмотренному «SupTech» и предполагает использование поднадзорными финансовыми организациями инновационных технологий в целях повышения эффективности выполнения регуляторных требований и управления рисками, что призвано ускорить исполнение требований внутреннего контроля при меньших затратах для финансовых организаций.

В 2017 г. Центральным Банком РФ были разработаны и утверждены Основные направления развития финансовых технологий на период 2018-2020 гг., определяющие первоочередные цели и задачи развития инновационных технологий на финансовом рынке и в Банке России, среди которых - поддержка инноваций и обеспечение доступности финансовых продуктов и услуг для населения и бизнеса; повышение доступности, качества и ассортимента финансовых услуг; содействие развитию конкуренции на финансовом рынке; повышение уровня конкурентоспособности российских технологий; снижение рисков и издержек в финансовой сфере. Устойчивое развитие и повышение конкурентоспособности российского финансового сектора будет производиться успешнее и эффективнее после реализации вышеназванных направлений [3].

Учитывая ранее рассмотренные цели, а также текущие экономические и технологические тренды, можно выделить главные направления и задачи Банка России в области развития финансовых технологий:

1. Правовое регулирование.

2. Развитие цифровых технологий на финансовом рынке, включающее в себя исследование, анализ и разработку предложений по применению финансовых технологий (RegTech, SupTech, Big Data и Smart Data, мобильные технологии, искусственный интеллект, роботизация и машинное обучение, биометрия, технология распределенных реестров, открытые интерфейсы);

3. Повсеместный переход к электронному взаимодействию.

На основании вышесказанного можно заключить, что экономическое воздействие цифровых технологий дает возможность глубоко изучить трансформацию ИКТ в стране и ее важнейшую роль в усилении инструментов финансового рынка. Для успешной интеграции цифровизации в финансовый рынок создаются все необходимые условия, благодаря которым повышается конкурентоспособность субъектов данного рынка, а также растет доступность и 
качество предоставляемых услуг. Технология - это только часть цифровой трансформации. Многое из того, что должно быть достигнуто в процессе трансформации, является культурным или пересекает границы во многих других частях организации, таких как маркетинг, PR, цепь поставок, розничные торговые точки и поддержка клиентов, чтобы охватить только некоторые из них. Это означает, что всем, кто приходит для проведения такой трансформации, должно быть предоставлено время для консультаций с целым рядом заинтересованных сторон, как для выяснения того, что такое текущая передовая практика, так и для выявления уникальных возможностей от использования цифровых технологий в финансовой сфере.

\section{Исследование выполнено при финансовой поддержке РФФИ в рамках научного проекта № 19-310-90035/19.}

\section{Список литературы:}

1. Распоряжение Правительства РФ от 28.07.2017 № 1632-р «Об утверждении программы «Цифровая экономика Российской Федерации»»». [Электронный ресурс]. Режим доступа: http://www.consultant.ru/document/cons_doc_LAW_221756/ (Дата обращения: 12.12.2019 г.).

2. Основные направления развития финансовых технологий на период 2018 - 2020 годов (Центральный банк РФ), Москва. [Электронный ресурс]. Режим доступа: https://www.cbr.ru/Content/Document/File/44185/onfr_201820(project).pdf (Дата обращения: 12.12.2019 г.).

3. Основные направления развития финансового рынка Российской Федерации на период 2019 - 2021 годов (Центральный банк РФ), Москва. [Электронный ресурс]. Режим доступа: https://www.cbr.ru/Content/Document/File/44185/onfr_2019-21(project).pdf. (Дата обращения: 12.12.2019 г.). 